\title{
Changing Expendable Bathythermograph Fall Rates and Their Impact on Estimates of Thermosteric Sea Level Rise
}

\author{
Susan E. Wijffels,* Josh Willis, ${ }^{+}$Catia M. Domingues,* Paul Barker,* Neil J. White,*,\# \\ Ann Gronell,* Ken Ridgway,* and John A. ChurCh*\# \\ * Centre for Australian Weather and Climate Research, Hobart, Tasmania, Australia \\ $+{ }^{+}$Jet Propulsion Laboratory, California Institute of Technology, Pasadena, California \\ \# Antarctic Climate and Ecosystem Cooperative Research Centre, Hobart, Tasmania, Australia
}

(Manuscript received 18 October 2007, in final form 4 March 2008)

\begin{abstract}
A time-varying warm bias in the global XBT data archive is demonstrated to be largely due to changes in the fall rate of XBT probes likely associated with small manufacturing changes at the factory. Deepreaching XBTs have a different fall rate history than shallow XBTs. Fall rates were fastest in the early 1970s, reached a minimum between 1975 and 1985, reached another maximum in the late 1980s and early 1990s, and have been declining since. Field XBT/CTD intercomparisons and a pseudoprofile technique based on satellite altimetry largely confirm this time history. A global correction is presented and applied to estimates of the thermosteric component of sea level rise. The XBT fall rate minimum from 1975 to 1985 appears as a 10-yr "warm period" in the global ocean in thermosteric sea level and heat content estimates using uncorrected data. Upon correction, the thermosteric sea level curve has reduced decadal variability and a larger, steadier long-term trend.
\end{abstract}

\section{Introduction}

Owing to their enormous heat capacity, the oceans are absorbing most of the excess heat trapped in the climate system by the increasing concentrations of greenhouse gases. Ocean heat content can thus be used as a metric to check whether coupled climate models are correctly responding to anthropogenic and natural forcing. However, greater accuracy is needed both for global averages and on smaller scales, as regional patterns of heat content change provide important clues to changes in wind fields and changes in air-sea heat fluxes and inform how local impacts may differ from global impacts. Generating such estimates with accuracy remains a huge challenge (Levitus et al. 2005), largely due to a paucity of data in much of the global ocean, especially south of the equator. Another problem also exists - that of the changing technology used to collect ocean temperature profiles. These changes may result in technology-related biases in estimates of

Corresponding author address: Susan E. Wijffels, CSIRO Marine and Atmospheric Research, GPO 1538, Hobart, 7000, TAS, Australia.

E-mail: susan.wijffels@csiro.au heat content. In the last few years, the rapidly expanding Argo array (Gould et al. 2004) is attempting to rectify many of the past problems in data quality and global coverage by delivering a truly global and highly quality controlled data stream of ocean temperature and salinity.

As the global ocean warms, its thermal expansion contributes to global sea level rise. Attempts to quantify the causes of global sea level rise-ocean thermal expansion, glacier and ice cap/sheet melting, snowpack reduction-are confounded by the problems noted above. While the mean rates of sea level rise over the past 100 years are of great importance, decadal variability is also of interest. Church et al. (2005) show that large volcanic eruptions cool the global ocean and produce a drop in global sea levels. While this volcanic signal is clear in appropriately forced models and the global tide gauge record, it is not as clear in the global thermosteric sea level record (the component of sea level change due to the thermal expansion of the ocean and closely related to ocean heat content), and there are several instances where global sea level is rising but steric sea level is falling, for example, 1980-83 (Fig. 1). Can these curves be reconciled?

Gouretski and Koltermann (2007) used an ocean cli- 


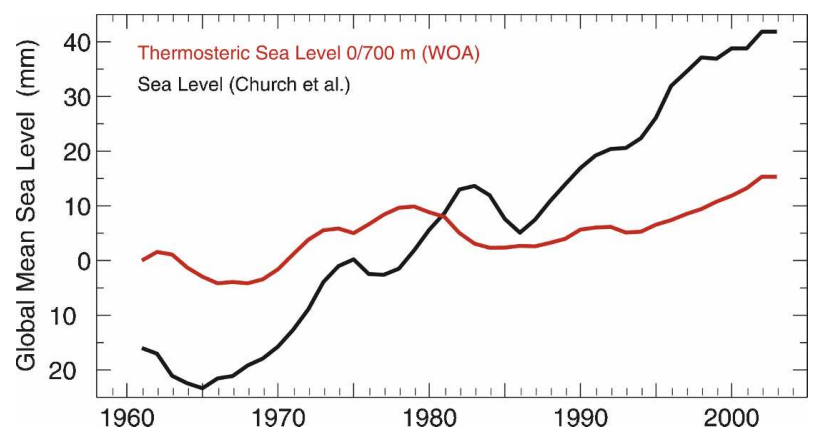

FIG. 1. Global mean sea level (black) and an estimate of the thermosteric component [World Ocean Atlas (WOA)] (red) in the upper $700 \mathrm{~m}$ based on the gridded temperature data and reference climatology used in Antonov et al. (2005) and Levitus et al. (2005). Note that these time series have an ad hoc reference and were smoothed by a 3 -yr running mean.

matology based on the highest quality data [Nansen casts and conductivity-temperature-depth (CTD) profiles] to compare how different instrument types measured the same ocean regions. Their study identified a clear warm bias in the abundant but low-accuracy data collected by expendable bathythermographs (XBTs). This bias appears to vary from year to year. They also showed its profound impact on estimates of the time history of total ocean heat content. Here we examine the bias identified by Gouretski and Koltermann (2007, hereafter GK) using a different method, diagnose the likely source of the error and recommend a correction.

\section{The fall rate problem}

XBTs were developed in the early 1960s at the request of the U.S. Navy (Seaver and Kuleshov 1982). The instrument is essentially a thermistor embedded in the nose of a hydrodynamic bulb with two spools of wire: one within the probe and one on the vessel that unwinds as the instrument free-falls from the surface to depth and the vessel steams away from the deployment location. The instrument collects a temperature versus time trace, with the latter converted to reported depth, $Z_{\mathrm{XBT}}$, using a "fall rate equation":

$$
Z_{\mathrm{XBT}}=A t-B t^{2},
$$

where $t$ is the elapsed time in seconds since the XBT hit the ocean surface.

The bulk of XBT temperature profiles were collected using probes manufactured by Sippican Incorporated (now Lockheed Martin Sippican). Between 1965 and the late 1990s Sippican probes were produced in the United States, after which their manufacture was moved to Mexico. However, the Sippican probe com- ponents have remained consistent, consisting of a plastic spool with a zinc nose weight and an afterbody wrapped in plastic-coated copper wire (Sippican 2007, personal communication). One component that has changed significantly is the XBT data system (recording mechanism), changing from analog to digital during the 1980s.

It has long been recognized that depth determination is the most likely source of error in XBT data (Roemmich and Cornuelle 1987). Since the mid-1970s comparison studies between simultaneous XBTs and CTDs have identified systematic errors in the computed XBT depths. Early results suggested that a small negative correction was required for the water above the thermocline, while a much larger positive correction was needed for depths below it (Fedorov et al. 1978; Flierl and Robinson 1977; McDowell 1977; Seaver and Kuleshov 1982). No official correction factor was adopted by Sippican until the early 1990s when Hanawa et al. (1995, hereafter H95) pooled and analyzed recent field intercomparisons against research-quality CTD data. Their comprehensive analysis of the field data unambiguously showed that using the manufacturer's fall rate equation resulted in deduced depths that were too shallow (and thus produced a cold temperature bias in most of the ocean). H95 recommended a new fall rate equation for Sippican and Tsurumi Seiki Co., Ltd. (TSK) XBTs, but recommended that it not be implemented until arrangements for adequate metadata reporting about the fall rate were put in place. As one reviewer notes: "Many data providers jumped the gun and implemented the correction immediately, leading to ambiguity (corrected/uncorrected) in data from the mid-1990s. Problems persist even to the present day since fall rate metadata are sometimes reported incorrectly."

It was also recommended that the reported depth for all past XBT profiles for which depth was found using the manufacturer's original fall rate equation should be corrected to the same effective equation by multiplying by a factor of 1.0336. Thus in the global archives of Boyer et al. (2006), much work was done to provide information on which XBT profiles needed correction (supplied using old manufacturer's fall rate equation) and which did not (i.e., those reported using the H95 fall rate equation). Despite this and, as noted above, the transition to the new fall rate equation occurred over many years, and not all contributors have provided the necessary or correct metadata.

\section{Data sources and methods}

Here we use temperature profiles assembled for the European Commission project for Ensembles-Based 
Predictions of Climate Changes and their Impacts (ENSEMBLES) by B. Ingleby and colleagues (Ingleby and Huddleston 2007, hereafter IH), and we use the Enhanced Ocean Data Assimilation and Climate Prediction (ENACT) archive version 3 (hereafter EN3), which used the methods of IH and the World Ocean Data Base 5 (WOD05) (Johnson et al. 2006) as a data source. The archive is a composite of historical data collected in the WOD05 (Boyer et al. 2006) and more recent data archived by the Global TemperatureSalinity Profile Programme (GTSPP) project (Wilson 1998). IH vertically decimate the data, carry out automated quality control tests and, in EN3, carry along some of the necessary metadata required to distinguish profiles collected using XBTs from those collected by other platforms such as CTDs and Nansen/Niskin bottle casts (hereafter referred to as bottles).

IH also corrected XBT profiles identified in WOD05 or GTSPP as requiring correction or "unknown" to the H95 fall rate standard. However, IH modified this correction for colder regions based on the work by Thadathil et al. (2002), who suggested that XBT fall rates are reduced by cold temperatures due to the increased kinematic viscosity of seawater.

To clarify and simplify our analysis, we reversed the cold temperature algorithm used by IH to revert all XBT data in EN3 to the H95 standard, effectively ensuring $f_{c}=1.0336$ for all XBTs of unknown type and those identified as requiring correction (i.e., those not submitted to the archives with the H95 fall rates already applied). Thus, all XBT profiles are adjusted to the H95 fall rate standard using the metadata available to us.

Before XBTs came into broadscale use in the late 1960s, the data archives are dominated by mechanical bathythermographs (MBTs) and bottle casts (Fig. 2). Shallow XBTs initially dominate the record (almost exclusively the T4 probes manufactured by Sippican, which only reach about 460-m depth), while in later years deeper-reaching probes (measuring to $750 \mathrm{~m}$ and more) such as the T7 and Deep Blue dominate the XBT archive. While other XBT manufacturers exist, Lockheed Martin Sippican's T4 and T7 probes are by far the dominant source of XBT profiles in the database. Before the early 1990s, the metadata in the archive do not reliably allow us to distinguish whether a profile was collected using a T4 or a T7. Therefore, we have used the maximum depth of an observation to differentiate between the two kinds of probes. We designate profiles where the maximum depth is less than or equal to 550 $\mathrm{m}$ as "shallow XBTs," which are predominantly T4s. Observations that extend beyond $550 \mathrm{~m}$ are designated "deep XBTs" which are predominantly T7s.
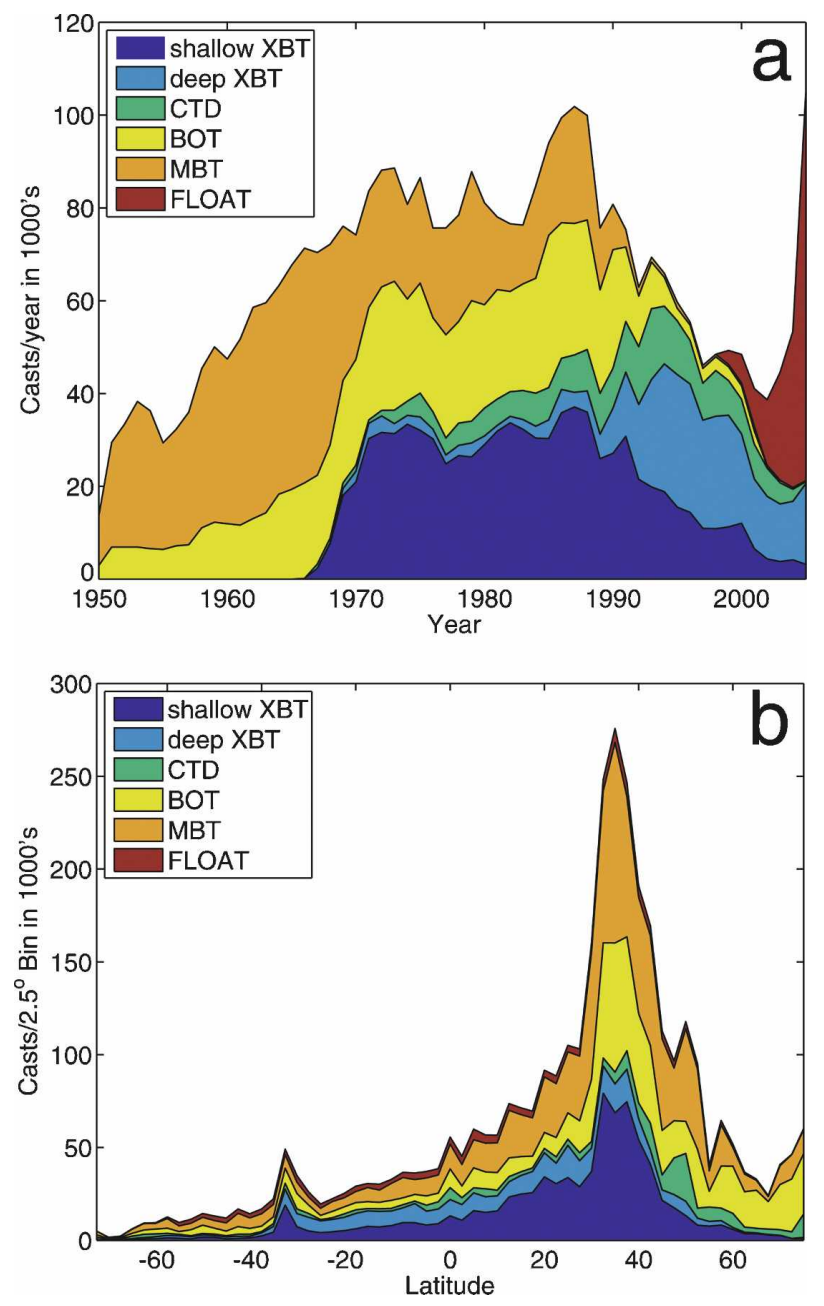

FIG. 2. Thousands of profiles (a) per year by platform in the EN3 archive and (b) in $2.5^{\circ}$ latitude bins, by platform type. See text for definitions of shallow and deep XBTs.

To explore the bias we first generate new global temperature climatologies for the upper $1000 \mathrm{~m}$ based on data from different instrument types. A local parametric fit in space and time is used following the method of Ridgway et al. (2002), where a two-dimensional spatial polynomial is locally fitted to temperature on a depth surface concurrently with annual and semiannual sinusoids at each depth. This approach can deal well with sparse data coverage as found in the Southern Hemisphere (where optimal averaging defaults to the first guess-usually a zero anomaly from a climatology), minimizes seasonal biasing and fits sharp mean ocean fronts well. However, we have extended this approach in two ways. The first is that we solve for a linear trend in time at each grid point so that the ocean warming trend is not misdiagnosed as a platform bias (Alory et al. 2007). The second extension is to use robust fitting 


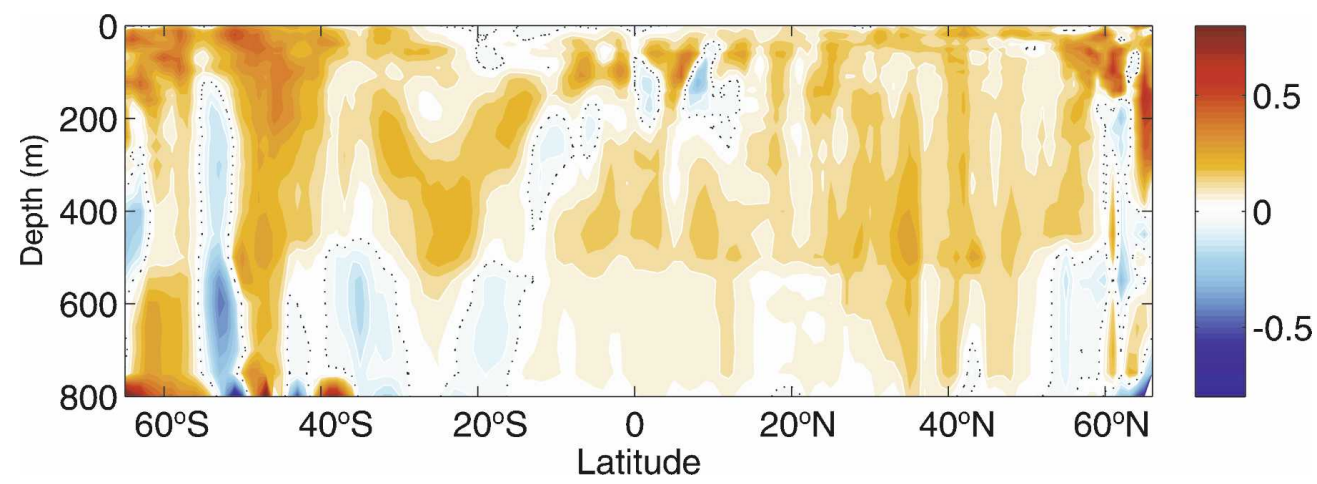

FIG. 3. Zonally averaged temperature difference between a climatology based on XBT data alone and one based on CTD and bottle casts. The zero contour is dashed in black, and the $0.1^{\circ} \mathrm{C}$ contours are shown in white.

methods that are less sensitive to outlier data and also provide error statistics on the fitted parameters. Here we used the method of Holland and Welsch (1977) as implemented by MATLAB ${ }^{\circledR}$ in the routine "robustfit."

After some experimentation, we found that fitted parameter estimates and errors generally stabilize when 1000 or more observations are locally fit around each $1^{\circ}$ $\times 1^{\circ}$ grid point, suggesting this is the number required to average over eddy noise. Thus, in data-sparse regions the data are collected from a large spatial footprint (radius of $3^{\circ}$ in longitude, $2^{\circ}$ in latitude), which shrinks in data-rich regions. Temperatures were fit on 41 depth levels, with a level every $10 \mathrm{~m}$ down to $150 \mathrm{~m}, 20 \mathrm{~m}$ down to 400-m depth, and $50 \mathrm{~m}$ down to 1000-m depth.

Three independent temperature climatologies are generated using data from the years 1960-2005: one based on XBTs only, one based on CTDs and bottles together, and one based on MBTs only. As the fit includes a linear trend, the reference year used to compare the climatologies is 1985 .

\section{The mean warm bias and its character}

The average warm bias of XBTs identified by GK is revealed by differencing the XBT and $\mathrm{CTD} /$ bottle based climatologies for the year 1985 (Fig. 3). At nearly all latitudes and in all ocean basins (Fig. 4) we find a warm bias of between $0.05^{\circ}$ and $0.3^{\circ} \mathrm{C}$. The bias is small but positive $\left(\sim 0.04^{\circ} \mathrm{C}\right)$ near the surface, is a maximum in the tropical thermocline, and is more uniform below that.

One striking feature, though, is that at around $500 \mathrm{~m}$ the bias drops to smaller values in deeper waters. The fact that the temperature biases have a depth dependence-small near the surface and a maximum in the strong tropical thermocline-strongly points toward a fall rate error. There is a consistent change in the bias around $500 \mathrm{~m}$ (Fig. 4), the maximum depth reached by the T4 probes. This implies that shallow XBTs may have a different bias from deep XBTs. Poleward of about $45^{\circ} \mathrm{S}$ and $55^{\circ} \mathrm{N}$ the bias is less clear, and this is likely due to the larger mapping errors associated with strong fronts and currents, smaller vertical temperature gradients reducing the detectability of a depth error, and scarce data in the subantarctic and Arctic regions. In addition, some work suggests that fall rates are affected by ambient densities (e.g., Thadathil et al. 2002), but our data might not be adequate to address this issue.

As fall rate errors are the most likely source of biases in XBTs, the temperature errors are converted into depth reading errors using the local temperature gradient to see whether the resulting error has the right characteristics for a fall rate bias-linearly increasing with

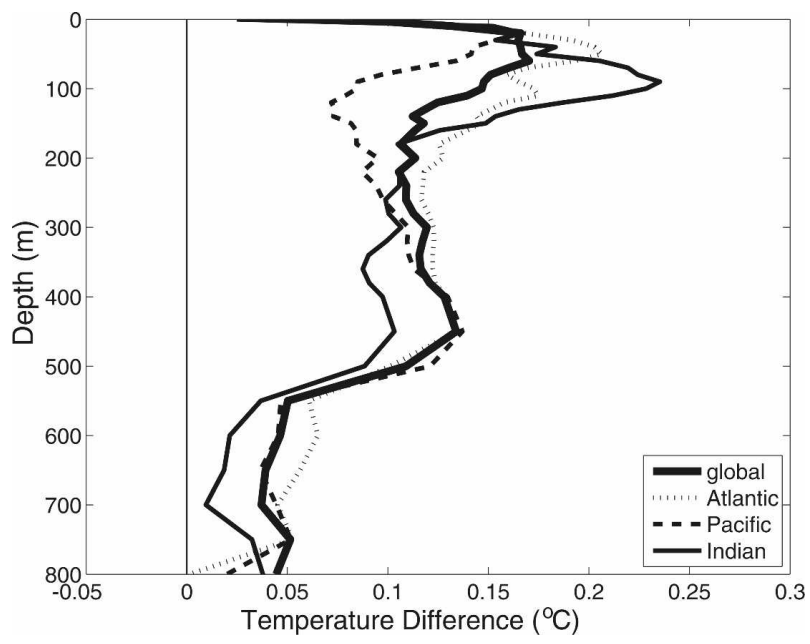

FIG. 4. Global and basin-averaged temperature difference between a climatology based on XBT data alone and one based on CTD and bottle casts for the global ocean. 


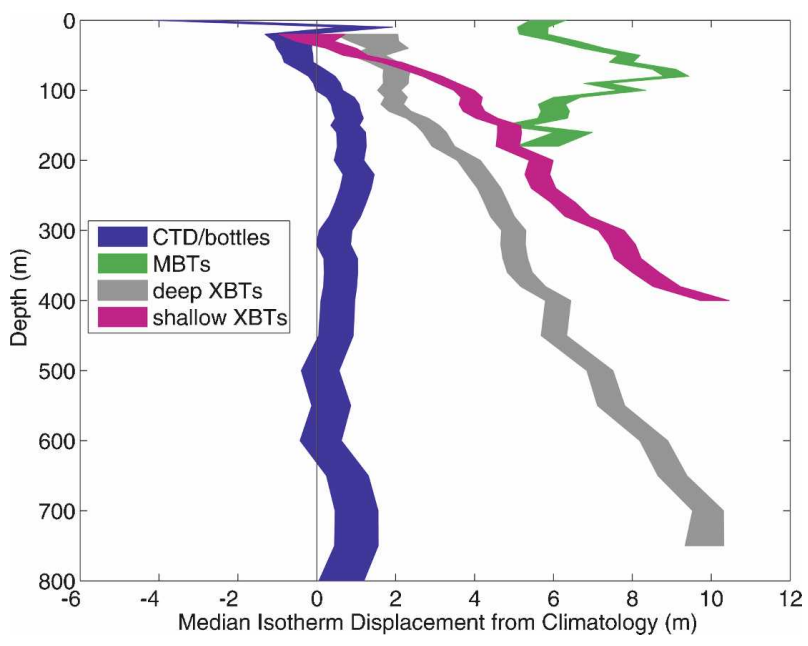

FIG. 5. Global and basin-averaged depth errors across all years diagnosed from individual profile data using temperature residuals from a climatology based on CTD and bottle casts for the global ocean and the years 1969-2005. The thickness of the curves is the standard error around the mean of the estimates, assuming every profile is independent. This latter assumption is likely optimistic and the true error may be at least twice as large as shown.

depth (Willis et al. 2008). We take into account the strong seasonal cycle and secular temperature trends in the upper ocean by performing the conversion of temperature residual into a depth error estimate profile by profile. Thus, for each identified XBT profile, a mapped equivalent for the right year, location, and season is generated using our bottle/CTD climatology. The resulting temperature residual is then converted to a depth error using the appropriate climatological temperature gradient as follows:

$$
d Z=d T_{\mathrm{xbt}} /\left(\partial T_{\mathrm{clim}} / \partial z\right) .
$$

Here, $d Z$ is the depth error, $d T_{\mathrm{xbt}}$ is the temperature residual and $\partial T_{\text {clim }} / \partial z$ is the local climatological temperature gradient.

The individual cast depth errors, like their associated temperature residuals, are dominated by eddy variability and thus massive averaging is required to identify the small shift in the central tendency. Averaged globally and over all years the XBT depth errors do, indeed, show a linear dependence on depth that we argue is diagnostic of a fall rate error (Fig. 5). As suggested by Figs. 3 and 4, shallow XBTs have a significantly larger depth bias than deep XBTs, with depth errors of $10 \mathrm{~m}$ near 400-m depth compared to $5 \mathrm{~m}$ for deep XBTs. The averaged depth error in CTD and bottle casts is barely distinguishable from zero, which is a reassuring confirmation of the method. Near the surface estimates are noisy as the vertical temperature gradient is small there, and thus the depth error is not well defined. Interestingly, MBTs show a rough 6-m depth error with a structure that is not at all linear in depth. As we do not understand the source of this error in MBTs, we do not attempt to model and remove it. For this reason, we recommend that MBTs be excluded from studies requiring depth accuracy of $<5 \mathrm{~m}$.

\section{Time dependency}

While it is encouraging that the XBT temperature bias appears to be caused by fall rate errors that may be correctable, GK clearly show that this bias is not stable over time. Correction to the archive will only be possible if the data bias across the archive follows a common time history. To explore this possibility, the depth errors were averaged in different ocean basins, and also in different latitude bins. As many agencies stockpile XBTs over periods of 1-2 yr (sometimes longer) our time resolution will be biennial at best, so analyses were carried out in overlapping 2-yr bins.

Remarkably, we find that a common time history does exist in the depth errors (Fig. 6). For example, the diagnosed mean depth errors at $600 \mathrm{~m}$ for deep XBTs in the separate ocean basins vary together, with a minimum bias in 1985-90 and maxima in 1978 and 2005 (Fig. 6). The shallow XBTs show a similar variation but with a different magnitude of bias in the later years. Natural ocean variability does not vary uniformly in space (that is with all basins and latitudes in synchronicity) and is unlikely to vary in a way that generates a linearly increasing depth error. Therefore, the most likely source of the common time history in the depth bias of XBTs are subtle manufacturing changes at the XBT factory, which affect the fall rates of entire batches of probes.

At the suggestion of a reviewer we checked the time history of the bias in the northwest Pacific where large numbers of profiles were collected using XBTs manufactured by TSK. This region does, indeed, feature a depth-bias time history that is different from the other basins (Figs. 6d,h), though care must be taken when averaging over a small region as ocean variability may impact the results more.

A correction is fit to the diagnosed depth biases, where the depth error is modeled as a simple multiplicative factor of depth, $r$, defined such that $r=\left[Z_{\mathrm{XBT}}-\right.$ $\left.Z_{\text {true }}\right] / Z_{\text {XBT }}$.

Attempts were made to include an offset term, as well as a multiplicative factor, but the former was not stable between subsets of the archive. The fit was performed on each profile and then bin averaged. Errors 

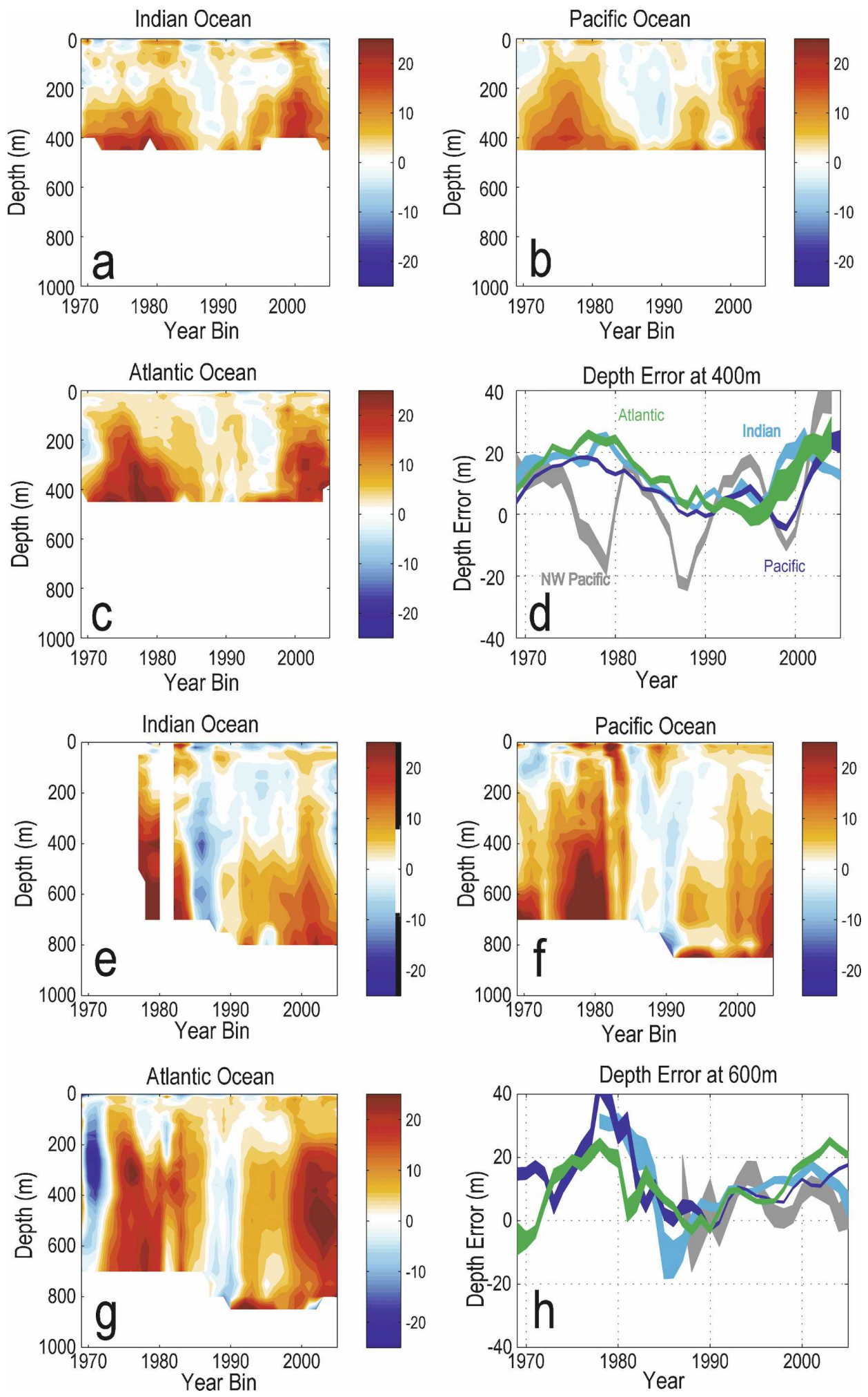

FIG. 6. Depth error time history for each ocean basin analyzed independently. Depth errors were averaged in 2-yr bins and in each ocean basin. For shallow XBTs in the (a) Indian, (b) Pacific, and (c) Atlantic Oceans; (d) shallow XBT depth error at $400 \mathrm{~m}$ for each basin with the Indian, Pacific, and Atlantic Oceans in cyan, blue, and green, respectively, with the northwest Pacific (longitudes $<155^{\circ} \mathrm{E}$, latitudes $>25^{\circ} \mathrm{N}$ ) in gray; For deep XBTs in the (e) Indian, (f) Pacific, and (g) Atlantic Oceans; (h) deep XBT depth error at $600 \mathrm{~m}$ for each basin with colors as in (d). In (d) and (h), curve thicknesses indicate the standard error of the estimate. 

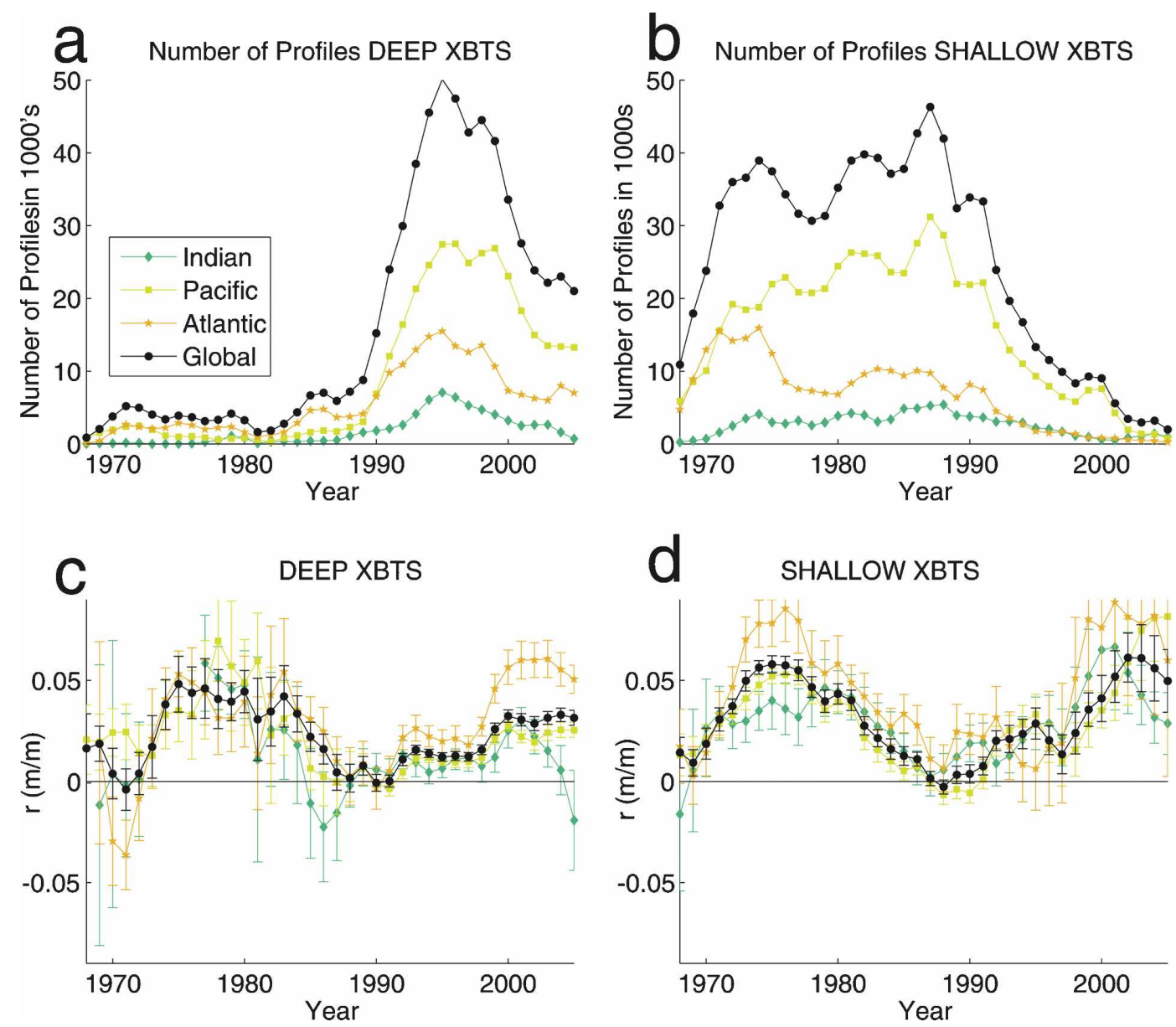

FIG. 7. Number of observations in 2-yr bins for (a) deep and (b) shallow XBTs. XBT depth correction factor, $r$, averaged in overlapping 2-yr bins for (c) deep- and (d) shallow-reaching profiles. Observation number [(a) and (b)] and fits [(c) and (d)] were analyzed in each ocean basin independently, as well as globally (see legend). Errors shown are 3 times the standard error, which encompasses $99.8 \%$ of the distribution (see text).

are bootstrapped, whereby $25 \%$ of the individual profiles in each pool are randomly sampled to produce a 50-member solution ensemble whose standard deviation is used to determine the error levels. Using a simple multiplicative factor to model depth error results in a remarkably reproducible time history between ocean basins (Fig. 7), though in recent years for deep probes we see some spread between ocean basins that might be due to incorrect metadata about reported fall rates.

Both types of XBTs show small biases (relative to the H95 fall rate) in the early 1970s, just after XBTs came into widespread use. After this period, the bias grows, reaching a $6 \%$ error in the late 1970 s. After this time, the error quickly returns to near zero when H95 reexamined fall rates and set the new international standard, confirming the accuracy of the H95 results throughout the late 1980s and early 1990s. In the mid- 1990s however, we see two distinct changes in the much more numerous deep XBTs-one near 1992 and another larger change in 1999. The latter change may be associated with a shift in manufacturing site from the United States to Mexico.

The diagnosed error factors also help explain the pattern of the mean temperature bias (Fig. 3). When shallow XBTs are very numerous and dominate the global archive $(1972-85)$ their mean depth bias is 5\%-6\%. After 1990, deep XBTs dominate the archive with a depth bias of only $2.5 \%$. Most of the shallow XBTs deployed globally have a large depth bias, while most deep XBTs had a depth bias roughly half as large. Thus, over the entire archive, temperatures below $500 \mathrm{~m}$ have a smaller warm bias than those above. Depth errors, $r$, diagnosed from EN3, are reported in Table 1 such that

$$
Z_{\text {true }}=Z_{\mathrm{XBT}}(1-r) \text {. }
$$


TABLE 1. Diagnosed depth errors as a fraction of depth, i.e., $r=$ (depth error)/depth based on the analysis of the EN3 archive where all profiles have been adjusted to the H95 fall rates. Fractional depth errors for shallow XBTs are indicated by $r_{s}$ and for deep XBTs by $r_{d}$. Errors shown encompass the 99th percentile based on a bootstrap analysis (see text).

\begin{tabular}{lcccc}
\hline \hline Year & $r_{s}$ & Error $r_{s}$ & \multicolumn{1}{c}{$r_{d}$} & Error $r_{d}$ \\
\hline 1968 & 0.014 & 0.008 & 0.016 & 0.017 \\
1969 & 0.009 & 0.007 & 0.019 & 0.009 \\
1970 & 0.019 & 0.008 & 0.004 & 0.013 \\
1971 & 0.031 & 0.006 & -0.004 & 0.010 \\
1972 & 0.037 & 0.004 & 0.004 & 0.010 \\
1973 & 0.050 & 0.005 & 0.017 & 0.015 \\
1974 & 0.056 & 0.003 & 0.038 & 0.012 \\
1975 & 0.058 & 0.004 & 0.048 & 0.014 \\
1976 & 0.057 & 0.005 & 0.044 & 0.013 \\
1977 & 0.055 & 0.005 & 0.046 & 0.015 \\
1978 & 0.047 & 0.005 & 0.041 & 0.015 \\
1979 & 0.040 & 0.006 & 0.039 & 0.009 \\
1980 & 0.043 & 0.005 & 0.044 & 0.010 \\
1981 & 0.040 & 0.005 & 0.031 & 0.020 \\
1982 & 0.028 & 0.005 & 0.035 & 0.017 \\
1983 & 0.021 & 0.004 & 0.042 & 0.015 \\
1984 & 0.016 & 0.005 & 0.033 & 0.009 \\
1985 & 0.013 & 0.005 & 0.022 & 0.007 \\
1986 & 0.011 & 0.003 & 0.016 & 0.007 \\
1987 & 0.001 & 0.003 & 0.005 & 0.009 \\
1988 & -0.003 & 0.004 & 0.002 & 0.007 \\
1989 & 0.003 & 0.004 & 0.008 & 0.005 \\
1990 & 0.004 & 0.005 & -0.001 & 0.004 \\
1991 & 0.008 & 0.004 & 0.000 & 0.003 \\
1992 & 0.020 & 0.005 & 0.011 & 0.003 \\
1993 & 0.021 & 0.007 & 0.016 & 0.002 \\
1994 & 0.024 & 0.007 & 0.014 & 0.002 \\
1995 & 0.029 & 0.008 & 0.012 & 0.002 \\
1996 & 0.020 & 0.007 & 0.013 & 0.002 \\
1997 & 0.013 & 0.010 & 0.012 & 0.002 \\
1998 & 0.024 & 0.010 & 0.016 & 0.002 \\
1999 & 0.036 & 0.008 & 0.026 & 0.003 \\
2000 & 0.041 & 0.011 & 0.032 & 0.003 \\
2001 & 0.052 & 0.013 & 0.031 & 0.003 \\
2002 & 0.061 & 0.012 & 0.032 & 0.003 \\
2003 & 0.061 & 0.017 & 0.003 \\
2004 & 0.056 & 0.016 & 0.003 \\
2005 & 0.050 & 0.016 & & \\
\hline & & & & \\
1993 & 0.004 \\
\hline
\end{tabular}

\section{Comparisons with independent methods}

Given the complexities and uncertainties of how XBT data are collected (recorder type, ship speed, probe source) and archived (accurate metadata for probe type and fall rate) the derivation of a global correction based simply on year of deployment and depth of measurement would appear naive. Attempting to retrieve the correct metadata to attack this problem in more detail far into the past archive is a very daunting task and it is likely impossible to achieve $100 \%$ accuracy. However, the fall rate changes that we have diag- nosed since the early 1990s can indeed be independently checked. Based on H95's recommendations, greatly improved metadata was collected for a larger portion of profiles sent to the global archives from the early 1990s onward. In addition, the XBT data can be checked against independent contemporaneous dataeither in situ CTD data or altimetric satellite data. Here we use these methods to check our depth error estimates.

\section{a. Altimetric pseudotemperature method}

Another powerful technique for characterizing the XBT bias is analysis of nearby XBT/CTD pairs as described in Willis et al. (2008). The technique is limited by the number of nearby XBT/CTD pairs. Since the early 1990s, however, satellite altimeters have provided global measurements of sea surface height (SSH) variability with excellent spatial and temporal resolution. A number of studies (e.g., Gilson et al. 1998; Willis et al. 2004) have shown that SSH anomalies are strongly correlated with upper-ocean temperature variability. By exploiting this correlation along with improved metadata since the early 1990s, it is possible to use the altimeter data to characterize recent XBT biases in much greater detail than for earlier periods.

The "Upd" product containing gridded SSH anomalies from Archiving, Validation, and Interpretation of Satellite Oceanographic data (AVISO) were used for this analysis. This product contains data from several satellite altimeters and includes variability on scales as small as 10 days and 150-200 km (Ducet et al. 2000).

For this part of the analysis, CTD data were obtained directly from both the GTSPP and WOD05 databases, and Argo profile data were obtained from the Argo array of profiling floats (Gould et al. 2004). XBT data were obtained from GTSPP, and, as above, all recommendations about application of the H95 depth correction were followed and probes of unknown type (GTSPP \$DPC code 03) also had the H95 correction applied. Data quality flags provided by GTSPP were used to eliminate spurious profiles when available. In addition, a six standard deviation test was performed using profiles in approximate $10^{\circ} \times 10^{\circ}$, geographically similar boxes to eliminate additional gross outliers.

To use the SSH data to test for biases in XBT profiles, local linear regression coefficients were computed between SSH and subsurface temperatures using temperature profiles from CTDs and Argo floats. Argo profiles with spurious pressure values identified by Willis et al. (2008) were excluded from this calculation. The regression coefficients allow subsurface temperature 


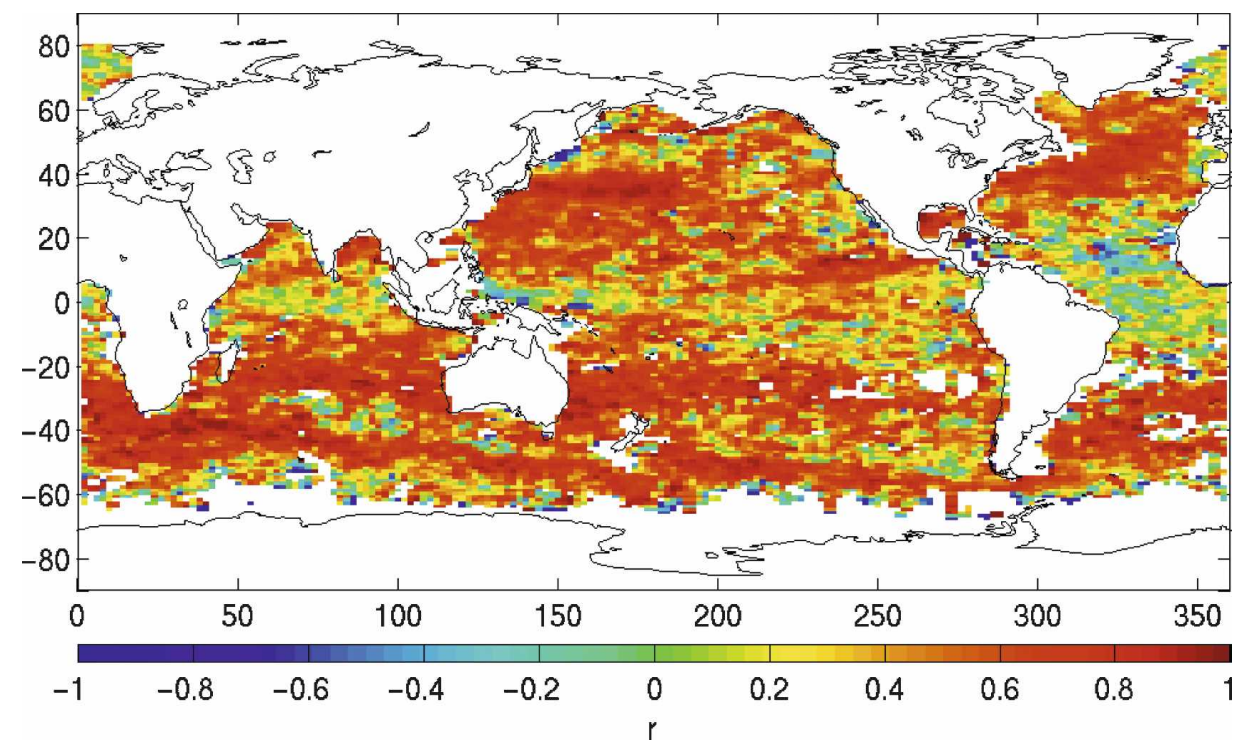

FIG. 8. Correlation coefficient between SSH and temperature anomaly at $400 \mathrm{~m}$.

anomalies to be estimated from SSH anomalies as follows:

$$
T_{\text {pseudo }}(z)=\alpha(x, y, z) \operatorname{SSH}(x, y, t),
$$

where, $\alpha(x, y, z)$ is a local regression coefficient and $T_{\text {pseudo }}$ is the estimate of subsurface temperature anomaly, referred to as the "pseudotemperature" profile.

Regression coefficients were computed in $2^{\circ}$ longitude $\times 1^{\circ}$ latitude bins on each $10-\mathrm{m}$ level depth from the surface to $750 \mathrm{~m}$. Temperature anomalies were computed relative to the World Ocean Circulation Experiment (WOCE) Gridded Hydrographic Climatology (WGHC) (Gouretski and Koltermann 2004). Figure 8 shows the correlation coefficient, $r$, between SSH and temperature anomaly at $400 \mathrm{~m}$. Note that in most regions, $r$ is greater than 0.5 .

Once the regression coefficients were computed, pseudotemperature profiles were estimated at the times and locations of all profiles from 1993 through the end of 2006. These "pseudopairs" were then used to examine the dependence of the XBT fall rate bias by probe type and manufacturer. The depth error was then estimated by differencing the observed temperature and the pseudotemperature and normalizing by $\partial T_{\text {clim }} / \partial z$ as described above. However, for the pseudopair analysis the WGHC climatology was used to compute $\partial T_{\text {clim }} / \partial z$ rather than the bottle/CTD climatology.

The pseudopair technique was first tested for consistency by estimating the depth error for CTD and Argo profiles. Figure 9 shows the median depth difference between CTD profiles and their pseudotemperature pairs, grouped in 1-yr increments from 1993 through 2002. With only a few thousand pairs per year, the depth differences range from 3 to $5 \mathrm{~m}$. Nevertheless, the lack of any time dependence and the proximity to zero suggest that the altimeter data provides a stable, accurate tool for determining depth errors during the altimeter record.

Also shown in Fig. 9 is a pseudopair analysis of Argo data by float type. This serves primarily as a consistency check of the technique as the floats provide most of the data used to determine the regression coefficients, $\alpha(x, y, z)$. Apart from the known bias in a number of Sounding Oceanographic Lagrangian Observer (SOLO) floats from the Woods Hole Oceanographic Institution (Willis et al. 2008), most float types have profiles with nearly zero depth error relative to the pseudopairs, as expected. The Provor and Autonomous Profiling Explorer (APEX) floats with Falmouth Scientific, Inc., (FSI) sensors do show slight offsets below $300 \mathrm{~m}$, but with only 6000 and 1200 pseudopairs, respectively, there are too few of these profiles to determine whether these small offsets are significant.

The pseudopair technique provides an independent estimate of temperature anomaly for each individual profile. However, the altimeter data still do not resolve eddy or internal wave variability on scales smaller than about $150 \mathrm{~km}$ and 10 days time. For this reason, significant averaging is still necessary to produce a robust estimate of XBT data errors. Nevertheless, this technique requires fewer pairs than a direct comparison between XBT profiles with nearby CTD and Argo profiles. This is illustrated in Fig. 10, which shows the fre- 


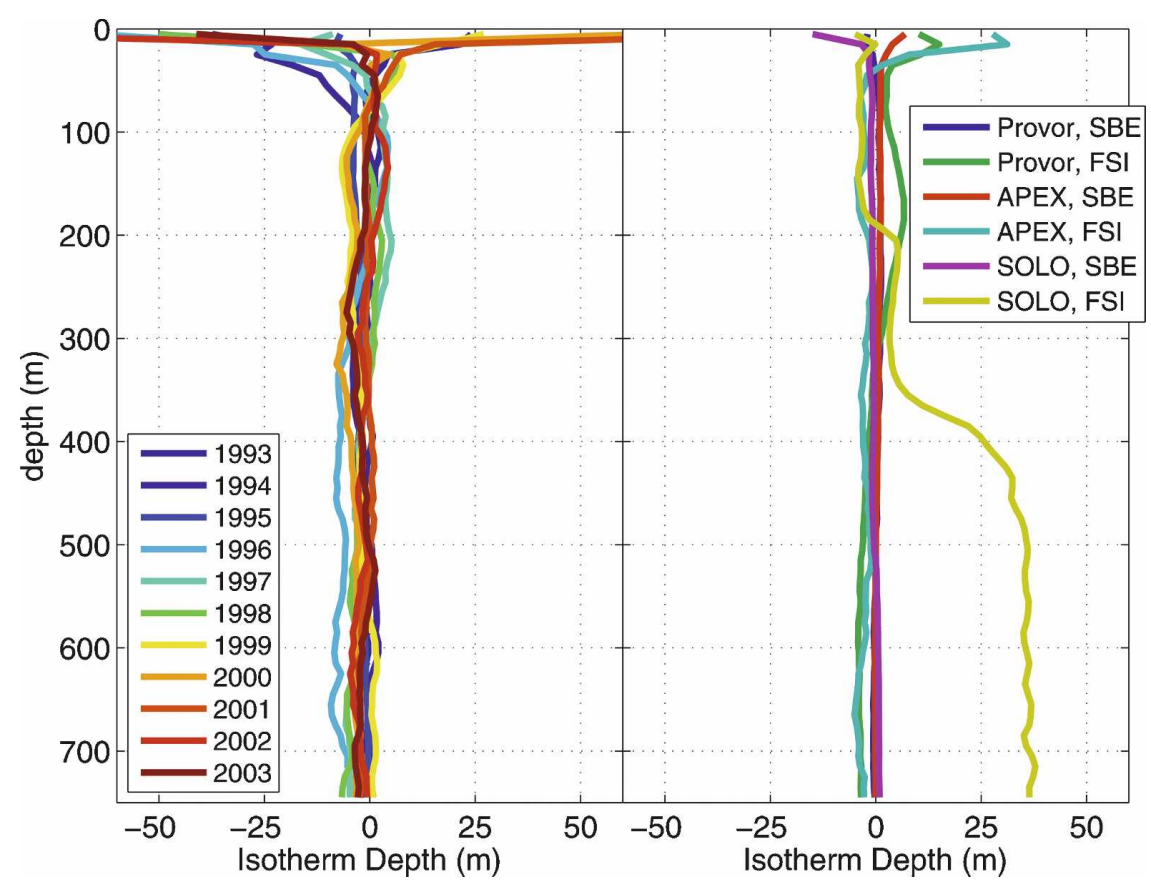

FIG. 9. (left) Median depth error computed by comparing actual CTD profiles and their "pseudopairs." Number of profiles ranges from 2000 to 6000 CTD profiles in a given year. (right) Median depth error computed for Argo float profiles by float type.

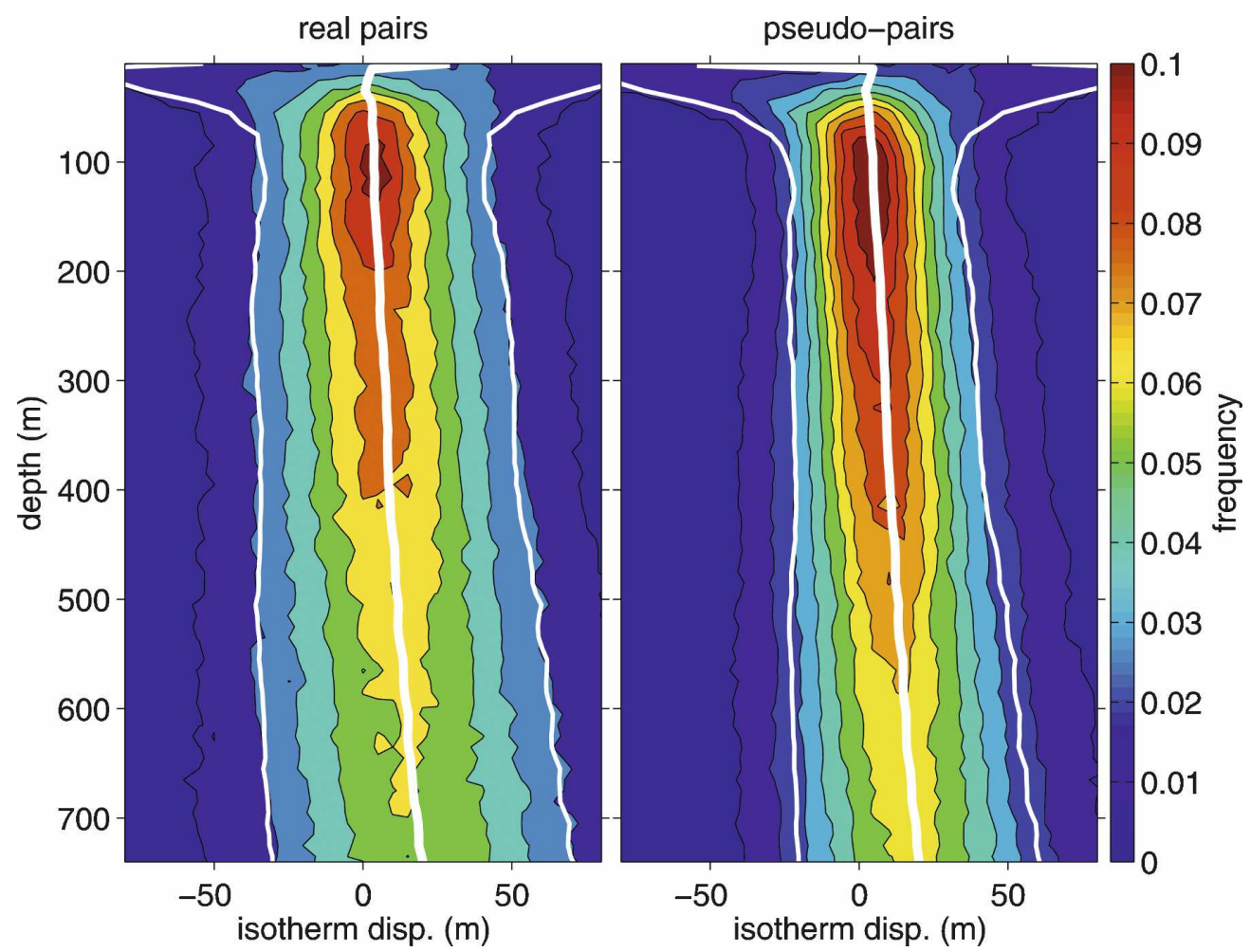

FIG. 10. Frequency distribution of difference in isotherm displacement vs depth for Sippican Deep Blue XBT probe with H95 fall rate coefficients (WMO code 052) compared with (left) nearby Argo profiles and (right) pseudopairs. Average is over the 3-yr period from 1 Jan 2004 through 31 Dec 2006. White lines show the median and one standard deviation. 


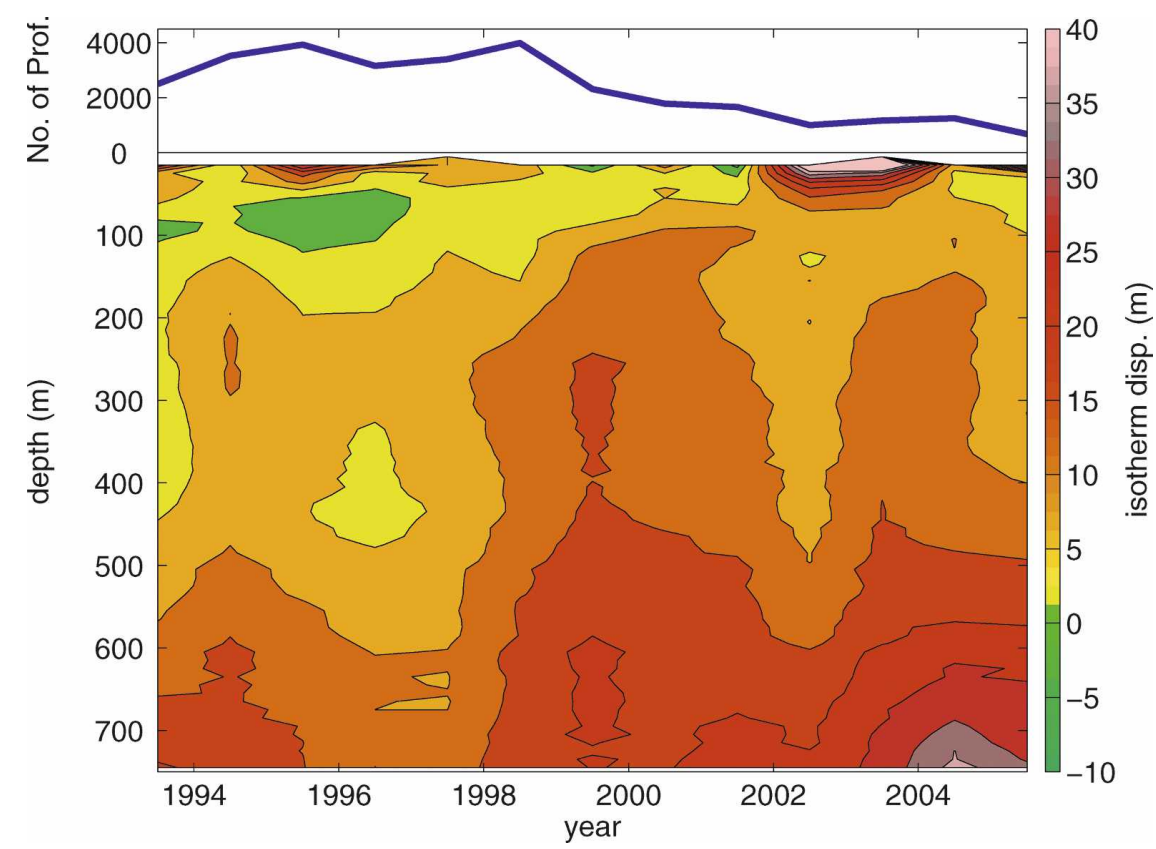

FIG. 11. Evolution of bias in for Sippican Deep Blue XBT probe with old fall rate coefficients (WMO code 051) using pseudopairs. The blue line shows the number of profiles used in a given year.

quency distribution versus depth of the pair analysis for Sippican Deep Blue XBT probe with H95 coefficients (WMO code 052) compared with nearby Argo profiles, over the 3-yr period from 1 January 2004 through 31 December 2006. Argo profiles were considered to be "nearby" if they fell within $4^{\circ}$ longitude, $2^{\circ}$ latitude and 90 days of an XBT probe. About 14000 such pairs were available during this period. The median value and one standard deviation range are highlighted. The frequency distribution of depth errors based on the pseudopair analysis for the same XBT probes is also shown in Fig. 10. Note that the median value is almost identical. However, the large time and space window needed to capture a sufficient number of Argo/XBT pairs results in a larger standard deviation for that technique. For the pseudopair technique, the altimeter data are interpolated to the time and location of the XBT profile, resulting in a one standard deviation range that is about $12 \mathrm{~m}$ smaller. This suggests that fewer pairs are needed for the pseudopair analysis technique to converge.

Figure 11 shows the temporal evolution of the depth bias in Sippican Deep Blue XBT probe with manufacturers original fall rate coefficients (WMO 1770 code 051) for each year from 1993 through 2005, based on the pseudopair analysis. About 30000 of these probes were deployed over the entire period and were more abundant during the 1990s. Note the sharp increase in the bias after 1999, again possibly reflecting changes in manufacturing that occurred after relocation of the main Sippican manufacturing facilities to Mexico.

Table 2 contains the temporal evolution of the depth biases of all probe types of substantial abundance in the GTSPP database computed using the pseudopair technique. As above, the depth error is modeled as a multiplicative factor of depth. Table 2 shows depth error, $r$, for each probe type and time period. Where there are fewer than 200 probes of a given type in a year, an analysis was not made. The error in $r$ is also computed using the same bootstrap method described above. In general, the pseudopair method confirms the results found in the EN3 analysis (Fig. 12). In particular, the steplike increase in bias among deep XBT probes is confirmed for the abundant Deep Blue probes and the shallow probes. However, for the probes indentified as T7s (Fig. 12b), there is marked divergence from the EN3 correction in certain years and the amplitude is close to that expected if probes are either uncorrected or double corrected with the depth factor 1.0336 suggested by $\mathrm{H} 95$. This illustrates a possibly serious problem with the metadata in the archives not being consistent with the fall rates used to determine depth.

It is important to note that the description of XBT biases presented in Table 2 may represent changes in data processing as well as any actual changes in instrument manufacture. In many profiles, ambiguities remain about which fall rate equations were used when the data were submitted to the archives. In the present 
TABLE 2. Diagnosed depth errors as a fraction of depth based on the altimetric pseudopair analysis. The data have been analyzed by WMO 1770 code number, which indicates whether the original or the H95 fall rate equation was used to find depth.

\begin{tabular}{|c|c|c|c|c|c|c|c|c|}
\hline Year & $r$ & Error & $r$ & Error & $r$ & Error & $r$ & Error \\
\hline & \multicolumn{8}{|c|}{ Probe } \\
\hline & \multicolumn{2}{|c|}{$\mathrm{T}-4$ original } & \multicolumn{2}{|c|}{ T-4 H95 } & \multicolumn{2}{|c|}{$\mathrm{T}-7$ original } & \multicolumn{2}{|c|}{ T-7 H95 } \\
\hline & \multicolumn{8}{|c|}{ WMO code } \\
\hline & \multicolumn{2}{|c|}{1} & \multicolumn{2}{|c|}{2} & \multicolumn{2}{|c|}{41} & \multicolumn{2}{|c|}{42} \\
\hline 1993 & 0.0322 & 0.0171 & - & - & 0.0246 & 0.0072 & - & - \\
\hline 1994 & 0.0342 & 0.0204 & - & - & 0.0255 & 0.0042 & - & - \\
\hline 1995 & 0.0573 & 0.0408 & 0.0328 & 0.0192 & 0.0262 & 0.0027 & 0.0189 & 0.0048 \\
\hline 1996 & 0.0670 & 0.0501 & 0.0324 & 0.0174 & 0.0243 & 0.0027 & 0.0187 & 0.0033 \\
\hline 1997 & 0.0478 & 0.0327 & 0.0277 & 0.0234 & 0.0154 & 0.0057 & 0.0180 & 0.003 \\
\hline 1998 & 0.0485 & 0.0165 & 0.0133 & 0.0498 & 0.0116 & 0.0099 & 0.0208 & 0.0039 \\
\hline 1999 & 0.0285 & 0.0297 & 0.0110 & 0.0735 & 0.0238 & 0.0162 & 0.0181 & 0.0051 \\
\hline 2000 & - & - & 0.0286 & 0.0357 & 0.0194 & 0.0135 & 0.0052 & 0.0039 \\
\hline 2001 & - & - & 0.0608 & 0.0207 & 0.0201 & 0.0126 & -0.0062 & 0.0063 \\
\hline 2002 & - & - & 0.0758 & 0.0135 & 0.0464 & 0.0132 & -0.0039 & 0.0096 \\
\hline 2003 & 0.0643 & 0.0417 & 0.0769 & 0.0123 & 0.0596 & 0.0153 & 0.0150 & 0.0111 \\
\hline 2004 & 0.0622 & 0.0354 & 0.0638 & 0.0114 & 0.0519 & 0.0159 & 0.0180 & 0.0108 \\
\hline 2005 & 0.0645 & 0.0393 & 0.0555 & 0.0141 & 0.0408 & 0.0177 & 0.0208 & 0.0141 \\
\hline 2006 & 0.0787 & 0.0384 & - & - & 0.0245 & 0.0195 & 0.0284 & 0.0279 \\
\hline
\end{tabular}

Probe

\begin{tabular}{|c|c|c|c|c|c|c|c|}
\hline \multicolumn{2}{|c|}{ T-DB original } & \multicolumn{2}{|c|}{ T-DB H95 } & & & & \\
\hline \multicolumn{4}{|c|}{ WMO code } & \multirow{2}{*}{\multicolumn{2}{|c|}{$\begin{array}{c}\text { Unknown, } \\
\text { depth } \sim 550 \mathrm{~m}\end{array}$}} & \multirow{2}{*}{\multicolumn{2}{|c|}{$\begin{array}{c}\text { Unknown, } \\
\text { depth } \sim 750 \mathrm{~m}\end{array}$}} \\
\hline \multicolumn{2}{|c|}{51} & \multicolumn{2}{|c|}{52} & & & & \\
\hline 0.0210 & 0.0048 & - & - & 0.0292 & 0.0066 & 0.0266 & 0.0024 \\
\hline 0.0211 & 0.0030 & - & - & 0.0241 & 0.009 & 0.0232 & 0.0021 \\
\hline 0.0193 & 0.0027 & 0.0098 & 0.0117 & 0.0148 & 0.0156 & 0.0212 & 0.0036 \\
\hline 0.0187 & 0.0033 & 0.0168 & 0.0033 & - & - & 0.0616 & 0.0084 \\
\hline 0.0193 & 0.0027 & 0.0164 & 0.0024 & - & - & 0.0586 & 0.0123 \\
\hline 0.0279 & 0.0030 & 0.0167 & 0.0021 & - & - & - & - \\
\hline 0.0351 & 0.0033 & 0.0218 & 0.0021 & - & - & - & - \\
\hline 0.0315 & 0.0045 & 0.0250 & 0.0021 & - & - & - & - \\
\hline 0.0292 & 0.0039 & 0.0218 & 0.0024 & - & - & - & - \\
\hline 0.0302 & 0.0042 & 0.0233 & 0.0021 & - & - & - & - \\
\hline 0.0335 & 0.0051 & 0.0245 & 0.0021 & - & - & - & - \\
\hline 0.0353 & 0.0054 & 0.0251 & 0.0024 & - & - & - & - \\
\hline 0.0314 & 0.0063 & 0.0282 & 0.0015 & - & - & - & - \\
\hline - & - & 0.0286 & 0.0024 & - & - & - & - \\
\hline
\end{tabular}

analysis, we have chosen to adopt the recommendations of GTSPP over whether or not to apply the H95 depth correction factor. However, further refinement of the bias estimate may be possible by considering additional metadata associated with the XBT profiles such as cruise number, data source, or profile history. With a more precise classification of XBT probe type and fall rate equation, bias in these instruments could be better characterized and minimized.

\section{b. Historical and recent in situ field comparisons}

It is also possible to compare the EN3-based history of fall rate changes with past field assessments. To do this we convert our slope error into an estimate of the first term, $A$, in the XBT depth equation (1). The variability in the second-order coefficient $B$ has a much weaker affect on depth estimates than changes in the first-order term $A$.

If $Z_{\text {true }}=A_{\text {true }} t-B t^{2}$ and $z_{\mathrm{XBT}}=A_{\mathrm{XBT}} t-B t^{2}$, where "true" is the actual fall rate parameters, and "XBT" refers to that used in EN3 (the H95 values), then ignoring the small changes in $B$ we can estimate the implied changes in the $A$ term via

$$
A_{\text {true }}=A_{\mathrm{XBT}}(1-r) \text {. }
$$

In addition to the field comparisons compiled by $\mathrm{H} 95$ in their Table 1, we also examine the additional in situ 

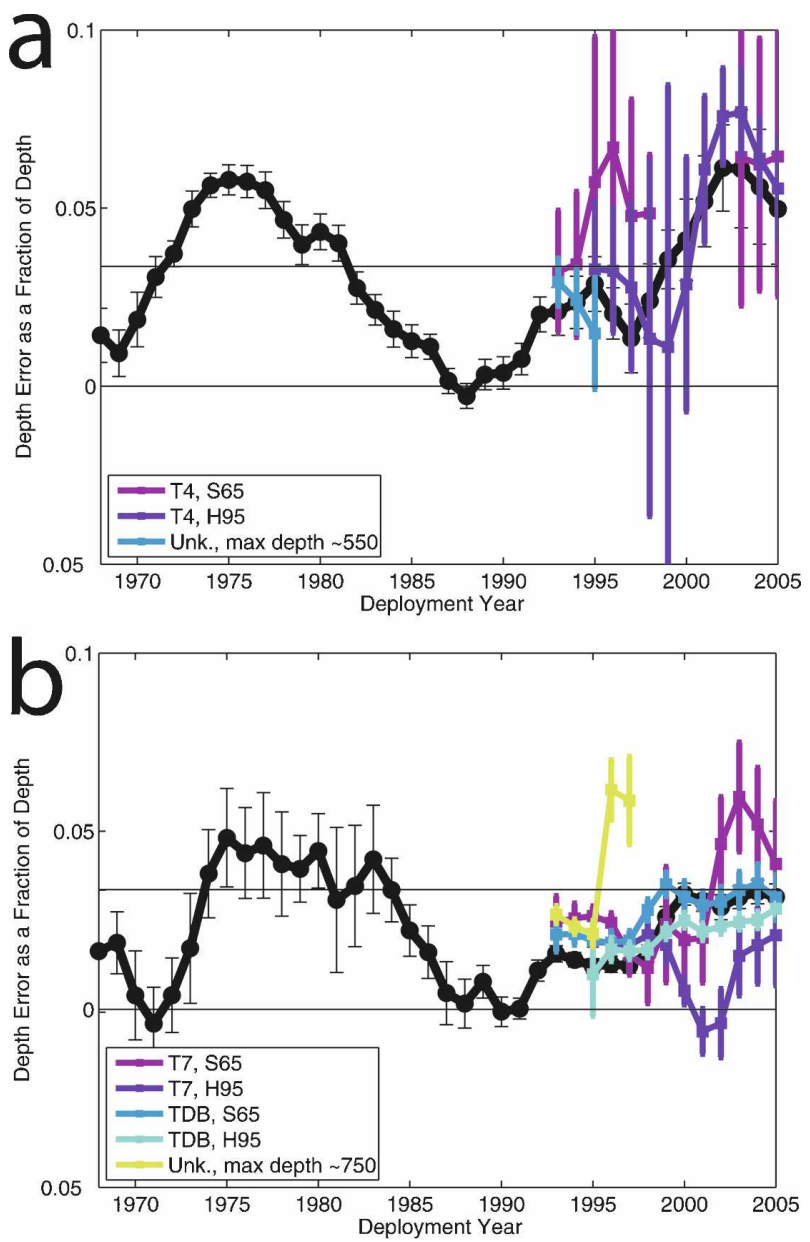

FIG. 12. In colors: the evolution of depth bias and its associated error (at $99 \%$ significance level) by probe type and depth equation used, as reported in Table 2. Results for (a) shallow XBT profiles and (b) deep XBT profiles. In the legend, T-7, T-4, and T-DB refer to Lockheed Martin Sippican's probe models identified by the WMO number in the profile metadata in the archive, with $\mathrm{H} 95$ and $\mathrm{S} 65$ indicating the reported fall rate equation used, where H95 refers to the Hanawa et al. (1995) recommendations and S65 indicates the manufacturers original estimate. The black line is the global bias estimated from EN3 with error bars as detailed in Table 1 . The two straight reference lines indicate fall rates equal the $\mathrm{H} 95$ value (at zero) and the S65 value (at 0.0366 ).

depth bias estimates listed in Table 3 where depth displacements are converted to an estimate of the $A$ term using the reasoning above.

An in situ CTD/XBT comparison was also carried out in 2001 in the Tasman and Coral Seas. During a high spatial-resolution CTD section, XBTs were dropped during each CTD cast providing a direct castby-cast comparison. The results show a clear warm bias in the XBT data (Fig. 13) and, when converted to a depth error, translates to a $3 \%$ overestimation of depth, agreeing with our analysis from EN3.

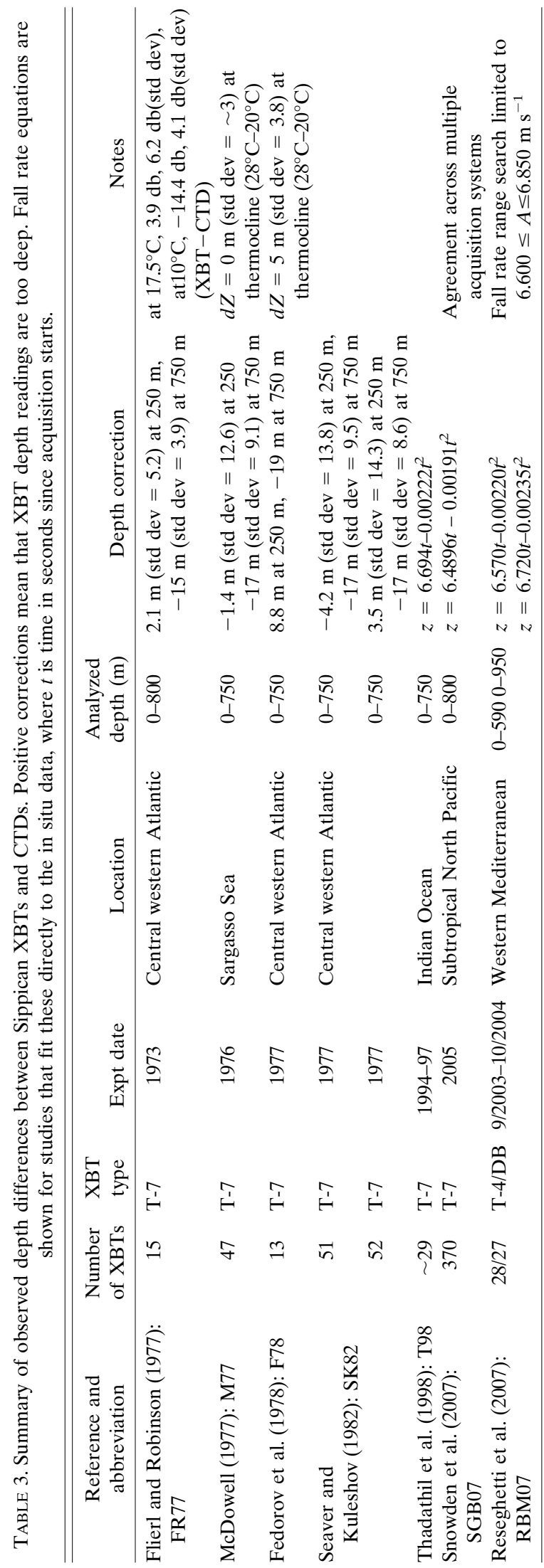


(a) July 2001
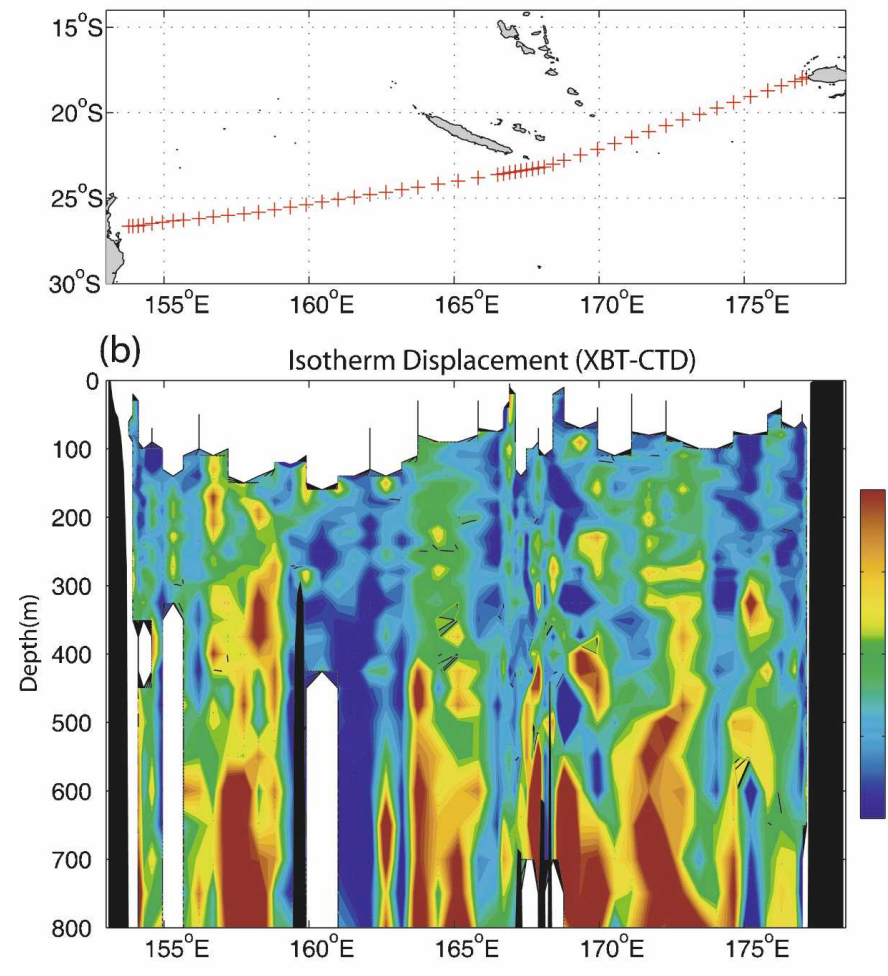

(c) XBT- CTD

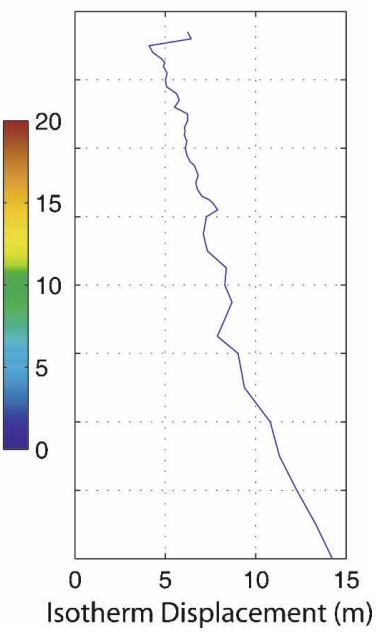

FIG. 13. During voyage of RV Franklin (July 2001) XBT casts were made concurrently at 52 CTD locations between Fiji and Brisbane. (a) Location of CTD stations; (b) difference in isotherm depth between XBT and CTD temperature casts. Blank areas show mixed layer and location of topography. (c) Mean difference in isotherm depth for XBT and CTD casts.

The deduced time history of the fall rate coefficient $A$ for deep XBTs (Fig. 14) based on EN3 agrees very well with most of the published results in the literature where fall rates were actually calculated-the values from H95 Table 1 (numbered), T98, and Snowden et al. (2007, hereafter SGB07). Ironically, the H95 assessment was done at a time when fall rates were faster than at any other time. The reduction of deep XBT fall rates since 1990 is independently confirmed by field intercomparisons (e.g., SGB07), as are the low values in the later 1970s. Before 1975 our estimate does not agree well with the depth errors in the literature, but at this time the number of deep XBTs in the database is quite small. The comprehensive study by Reseghetti et al. (2007, hereafter RBM07) also disagrees with SGB07's and our results for recent years. However, in their fitting of fall rate parameters to the in situ data, they did not allow for the low values of $A$ found by SGB07, and interestingly found a residual warm bias in their fall rate corrected temperature values. These recent studies raise serious questions, not just about the constancy of the fall rate equation, but also around its form.

\section{Summary and discussion}

An analysis of temperature and implied depth errors of the XBT profiles in EN3 confirm GK's findings that there is a time-variable warm bias in the XBT data. Here, we show that this bias is largely due to year-toyear changes in XBT fall rates and that shallow XBTs (T4s) have a different error from deep XBTs (T7s and Deep Blues). We believe it is highly likely that these are due to small changes in the manufacture of XBT probes since the changes are to first order spatially synchronized, have the vertical characteristics of a fall rate error, and are hard to explain in any other way. Our results are largely supported by historical and recent field intercomparisons between XBTs and CTDs, as well as a pseudoprofile technique based on satellite altimetry.

The XBT depth errors can be well modeled as a factor of total reported depth, and we present correction factors for the EN3 data up to 2005 (Table 1). It is crucial to note that these factors apply to XBT profiles that have been adjusted to the $\mathrm{H} 95$ fall rate equation. 


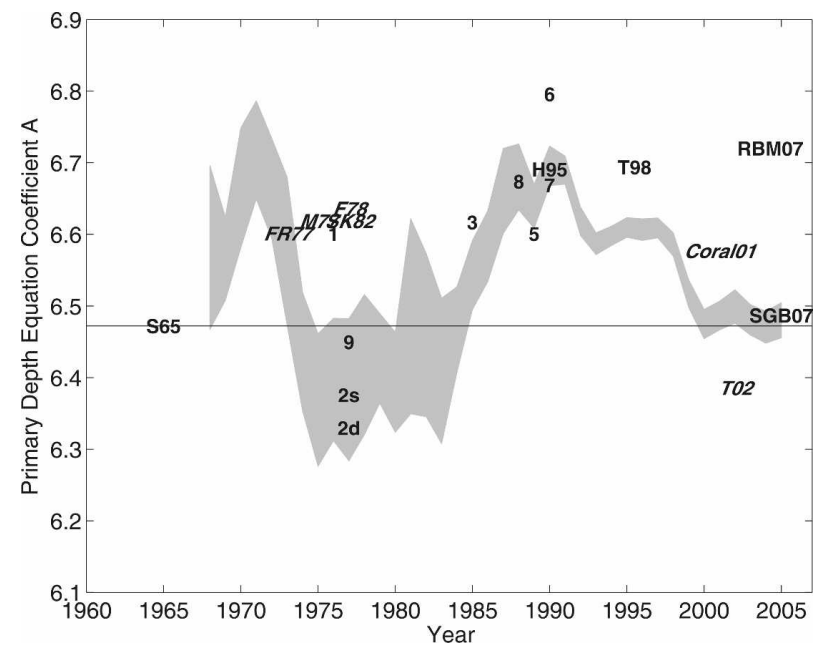

FIG. 14. Time history of the primary coefficient in the XBT fall rate equation for deep XBTs as estimated from our analysis of the XBTs in the EN3 dataset (gray line), estimates collated in H95's Table 1, and published results in Table 1 of this study. S65 refers to the manufacturer's recommended coefficient (also marked by the reference line), "Coral01" refers to an estimate based on an XBT/CTD field comparison carried out in the Coral Sea in 2001. Text symbols are centered on the time and value they represent.

Also, we do not assert that the suggested corrections account for all the bias errors in the archive across all contributing institutions, recorder, and probe-type combinations. Untangling this problem is extremely daunting, given the small amount of metadata for pre1990 profiles. Our results do suggest, encouragingly, that the bulk of the bias is common across these variations, and thus can be removed to first order. A more careful analysis using more of the available metadata is warranted, and it may be particularly worthwhile to revisit historical XBT/CTD intercomparison datasets to check the form and changing coefficients of the fall rate equation. SGB07 find a depth offset term in their dataset and our Coral Sea data support this. RBM07 find a residual temperature bias. This should also be further studied. In, addition, if XBT data are to be combined in analyses with other data types, some kind of ongoing batch calibration will be necessary, based either on annual field intercomparisons or using the pseudopair method discussed above. These issues present quite a challenge to the community.

Since XBT profiles make up more than $70 \%$ of the global temperature profile archive, the impact of these errors on estimates of global ocean heat content changes is large, as shown by GK. Using the spatial interpolation method of Church et al. (2004), and an unbiased XBT/CTD/bottle climatology as a reference, we estimate global ocean thermosteric sea level changes for the upper $700 \mathrm{~m}$ (Fig. 15). When corrected for the

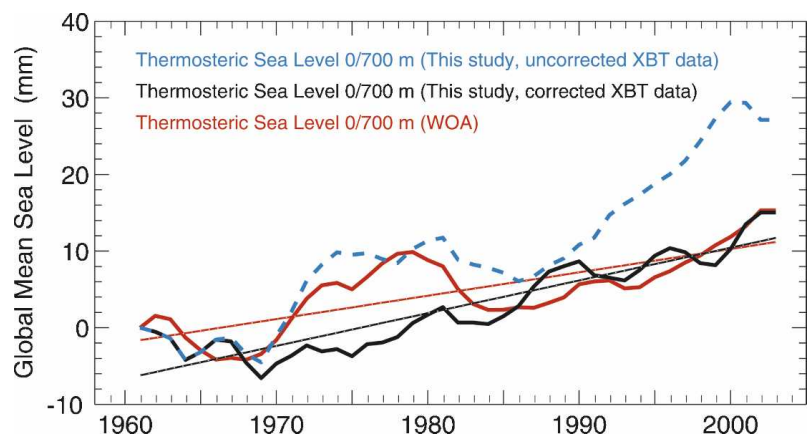

FIG. 15. Global mean thermosteric sea level estimates for the upper $700 \mathrm{~m}$, relative to 1961 . EN3 data, with (black) and without (blue) XBT profiles corrected for the fall rate bias, referenced to an unbiased climatology (see text for details). WOA estimates (red) based on the data and reference climatology used in Antonov et al. (2005) and Levitus et al. (2005). Note that, in this latter case, both data and the climatology contain XBT bias. The thin straight lines are least squares linear fits to the estimates. All time series were smoothed by a 3-yr running mean.

XBT bias, thermosteric sea level (and the associated ocean heat content) shows much weaker decadal variability in the 1970s and a higher rate of rise for 1961 to 2003 (e.g., compare the fitted linear trends). Though the endpoint values are similar, as found in GK the bias in the XBT data account for a large part of the 1970s decadal change in ocean heat content reported by Levitus et al. (2005). Based on the XBT bias corrections proposed here, Domingues et al. (2008) show that the average heat uptake in the upper $700 \mathrm{~m}$ of the ocean, from 1961 to 2003, accounts for a larger portion of sea level rise than previously believed. Their ocean warming and thermal expansion rates are about $50 \%$ larger than equivalent rates of earlier estimates (Antonov et al. 2005; Levitus et al. 2005; Ishii et al. 2006).

Acknowledgments. We thank Bruce Ingleby and the EN3 team for prompt help accessing their dataset and providing enhanced metadata to us. Suggestions by Bruce and two anonymous reviewers also improved this manuscript. This paper is a contribution to the CSIRO Climate Change Research Program and the CSIRO Wealth from Oceans Flagship and was supported by the Australian Government's Cooperative Research Centres Programme through the Antarctic Climate and Ecosystems Cooperative Research Centre. SEW, CMD, PAB, NJW, AG, KR, and JAC were partly funded by the Australian Climate Change Science Program. This research was carried out in part at the Jet Propulsion Laboratory, California Institute of Technology, under a contract with the National Aeronautics and Space Administration. 


\section{REFERENCES}

Alory, G., S. Wijffels, and G. M. Meyers, 2007: Observed temperature trends in the Indian Ocean over 1960-1999 and associated mechanisms. Geophys. Res. Lett., 34, L02606, doi:10.1029/2006GL028044.

Antonov, J. I., S. Levitus, and T. P. Boyer, 2005: Thermosteric sea level rise, 1955-2003. Geophys. Res. Lett., 32, L12602, doi:10.1029/2005GL023112.

Boyer, T. P., and Coauthors, 2006: World Ocean Database 2005. S. Levitus, Ed., NOAA Atlas NESDIS 60, 190 pp.

Church, J. A., N. J. White, R. Coleman, K. Lambeck, and J. X. Mitrovica, 2004: Estimates of the regional distribution of sea level rise over the 1950-2000 period. J. Climate, 17, 26092625.

_ _ _ and J. M. Arblaster, 2005: Significant decadal-scale impact of volcanic eruptions on sea level and ocean heat content. Nature, 438, 74-77.

Domingues, C. M., J. A. Church, N. J. White, P. J. Gleckler, S. E. Wijffels, P. M. Barker, and J. R. Dunn, 2008: Improved estimates of upper-ocean warming and multi-decadal sea-level rise. Nature, 453, 1090-1093.

Ducet, N., P.-Y. Le Traon, and G. Reverdin, 2000: Global highresolution mapping of ocean circulation from TOPEX/ Poseidon and ERS-1 and -2. J. Geophys. Res., 105, $19477-$ 19498.

Fedorov, K. N., A. I. Ginzburg, and A. G. Zatsepen, 1978: Systematic differences in isotherm depths derived from XBT and CTD data. POLYMODE News, F. Webster and C. Herrity, Eds., Vol. 50, Woods Hole Oceanographic Institution, 6-7.

Flierl, G., and A. R. Robinson, 1977: XBT measurements of the thermal gradient in the MODE eddy. J. Phys. Oceanogr., 7, 300-302.

Gilson, J., D. Roemmich, B. Cornuelle, and L.-L. Fu, 1998: Relationship of TOPEX/Poseidon altimetric height to steric height and circulation of the North Pacific. J. Geophys. Res., 103, 27 947-27 965.

Gould, J., and Coauthors, 2004: Argo profiling floats bring new era of in situ ocean observations. Eos, Trans. Amer. Geophys. Union, 85, 185.

Gouretski, V. V., and K. P. Koltermann, 2004: WOCE global hydrographic climatology. Berichte des Bundesamtes für Seeschifffahrt und Hydrographie 35, 52 pp. [Available online at http://odv.awi.de/en/data/ocean/woce_global_hydrographic_ climatology/.]

, and 2007: How much is the ocean really warming? Geophys. Res. Lett., 34, L01610, doi:10.1029/2006GL027834.

Hanawa, K., P. Rual, R. Bailey, A. Sy, and M. Szabados, 1995: A new depth-time equation for Sippican or TSK T-7, T-6 and T-4 expendable bathythermographs (XBT). Deep-Sea Res. I, 42, 1423-1451.

Holland, P. W., and R. E. Welsch, 1977: Robust regression using iteratively reweighted least-squares. Commun. Stat. Theory Methods, A6, 813-827.

Ingleby, B., and M. Huddleston, 2007: Quality control of ocean temperature and salinity profiles-Historical and real-time data. J. Mar. Syst., 65, 158-175, doi:10.1016/j.jmarsys.2005.11. 019 .

Ishii, M., M. Kimoto, K. Sakamoto, and S.-I. Iwasaki, 2006: Steric sea level changes estimated from historical ocean subsurface temperature and salinity analyses. J. Oceanogr., 62, 155-170.

Johnson, D. R., and Coauthors, 2006: World Ocean Database 2005 documentation. S. Levitus, Ed., NODC Internal Rep. $18,163 \mathrm{pp}$.

Levitus, S., J. Antonov, and T. Boyer, 2005: Warming of the world ocean, 1955-2003. Geophys. Res. Lett., 32, L02604, doi:10. 1029/2004GL021592.

McDowell, S., 1977: A note on XBT accuracy. POLYMODE News, F. Webster and C. Herrity, Eds., Vol. 29, Woods Hole Oceanographic Institution, 4-8.

Reseghetti, F., M. Borghini, and G. M. R. Manzella, 2007: Factors affecting the quality of XBT data-Results of analyses on profiles from the western Mediterranean Sea. Ocean Sci., 3, $59-75$.

Ridgway, K. R., J. R. Dunn, and J. L. Wilkin, 2002: Ocean interpolation by four-dimensional weighted least squaresApplication to the waters around Australasia. J. Atmos. Oceanic Technol., 19, 1357-1375.

Roemmich, D., and B. Cornuelle, 1987: Digitization and calibration of the expendable bathythermograph. Deep-Sea Res., 34, 299-307.

Seaver, G. A., and S. Kuleshov, 1982: Experimental and analytical error of expendable bathythermograph. J. Phys. Oceanogr., 12, 592-600.

Snowden, D., G. Goni, and M. Baringer, 2007: A comparison of six expendable bathythermograph data acquisition systems. AOML Draft Rep., 36 pp.

Thadathil, P., A. K. Ghosh, and P. M. Muraleedharan, 1998: An evaluation of XBT depth equations for the Indian Ocean. Deep-Sea Res. I, 45, 819-827.

——, A. K. Saran, V. V. Gopalakrishna, P. Vethamony, N. Araligidad, and R. Bailey, 2002: XBT fall rate in waters of extreme temperature: A case study in the Antarctic Ocean. $J$. Atmos. Oceanic Technol., 19, 391-396.

Willis, J. K., D. Roemmich, and B. Cornuelle, 2004: Interannual variability in upper ocean heat content, temperature, and thermosteric expansion on global scales. J. Geophys. Res., 109, C12036, doi:10.1029/2003JC002260.

, J. M. Lyman, G. C. Johnson, J. Gilson, 2008: In situ data biases and recent ocean heat content variability. J. Atmos. Oceanic Technol., in press.

Wilson, J. R., 1998: Global Temperature-Salinity Profile Programme (GTSPP)—Overview and future. Intergovernmental Oceanographic Commission Tech. Series 49, UNESCO, $33 \mathrm{pp}$. 